\title{
TENDÊNCIAS DA REFORMA SANTINARIA BRASILEIRA NOS INTELECTUAIS DO FÓRUM EM DEFESA DO SUS DO MUNICIPIO DE CAMPINA GRANDE/PB
}

\author{
Gerciane da Rocha Souza Andrade ${ }^{1}$ \\ Maria Joseli da Silva ${ }^{2}$ \\ Thaisa Simplício Carneiro Mathias ${ }^{3}$ \\ Alessandra Ximenes da Silva ${ }^{4}$
}

Resumo: A presente pesquisa de iniciação cientifica discute a Reforma Sanitária Brasileira (RSB) e suas respectivas bandeiras de lutas, seu desenvolvimento no processo de contrarreforma do Estado em curso, articulados na defesa do Sistema Único de Saúde (SUS) público, de qualidade e contra todas as formas de privatização da saúde. Este estudo apreende as proposições dos intelectuais coletivos que integram efetivamente o Fórum em Defesa do SUS de Campina Grande. Para tanto, identifica as propostas desses intelectuais no processo de contrarreforma da saúde em curso, na perspectiva do consenso ou da resistência, tendo como referência a Reforma Sanitária Brasileira formulada nos anos de 1980.

Palavras-chave: Intelectuais; Contrarreforma; Política de saúde.

\footnotetext{
1 Serviço Social/Universidade Estadual da Paraíba (UEPB), Brasil. E-mail: gerciane.souza.andrade@gmail.com.

2 Serviço Social/Universidade Estadual da Paraíba (UEPB), Brasil. E-mail: mjdessilva@gmmail.com.

${ }^{3}$ Serviço Social/Universidade Estadual da Paraíba (UEPB), Brasil. E-mail: thaisasimplicio@hotmail.com.

${ }^{4}$ Serviço Social/Universidade Estadual da Paraíba (UEPB), Brasil. E-mail: aleximenes@uol.com.br.
} 